\title{
Immunologic Dose-Response to Adenovirus-Vectored Vaccines in Animals and Humans: A Systematic Review of Dose-Response Studies of Replication Incompetent Adenoviral Vaccine Vectors when Given via an Intramuscular or Subcutaneous Route
}

\author{
Sara Afrough ${ }^{1, *}$, Sophie Rhodes ${ }^{2}$, Thomas Evans ${ }^{1}$, Richard White ${ }^{2}$ and John Benest ${ }^{2}$ \\ 1 Vaccitech Ltd., The Schrodinger Building, Heatley Road, The Oxford Science Park, Oxford OX4 4GE, UK; \\ tom.evans@vaccitech.co.uk \\ 2 Department of Infectious Disease Epidemiology, London School of Hygiene and Tropical Medicine, Keppel \\ Street, London WC1E 7HT, UK; Sophie.Rhodes@lshtm.ac.uk (S.R.); Richard.White@lshtm.ac.uk (R.W.); \\ John.Benest@lshtm.ac.uk (J.B.) \\ * Correspondence: sara.afrough@UCB.com
}

Received: 10 February 2020; Accepted: 10 March 2020; Published: 17 March 2020

check for updates

\begin{abstract}
Optimal vaccine dosing is important to ensure the greatest protection and safety. Analysis of dose-response data, from previous studies, may inform future studies to determine the optimal dose. Implementing more quantitative modelling approaches in vaccine dose finding have been recently suggested to accelerate vaccine development. Adenoviral vectored vaccines are in advanced stage of development for a variety of prophylactic and therapeutic indications, however dose-response has not yet been systematically determined. To further inform adenoviral vectored vaccines dose identification, historical dose-response data should be systematically reviewed. A systematic literature review was conducted to collate and describe the available dose-response studies for adenovirus vectored vaccines. Of 2787 papers identified by Medline search strategy, 35 were found to conform to pre-defined criteria. The majority of studies were in mice or humans and studied adenovirus serotype 5. Dose-response data were available for 12 different immunological responses. The majority of papers evaluated three dose levels, only two evaluated more than five dose levels. The most common dosing range was $10^{7}-10^{10}$ viral particles in mouse studies and $10^{8}-10^{11}$ viral particles in human studies. Data were available on adenovirus vaccine dose-response, primarily on adenovirus serotype 5 backbones and in mice and humans. These data could be used for quantitative adenoviral vectored vaccine dose optimisation analysis.
\end{abstract}

Keywords: dosing; dose-response; adenovirus-vectored vaccines; immunogenicity; clinical; pre-clinical

\section{Introduction}

The methods of finding doses for optimal vaccine delivery in humans is an empirical science. Frequently, vaccine developers have relied on historic information to conduct small dose-ranging studies in animal models, and then used these data to design further studies in humans, despite the relationship between animal and human dose being unproven [1]. Unlike allometric analysis used in pharmacokinetic/pharmacodynamic assessments in small molecule drug development [2], there are no published or widely accepted allometric scaling factors to easily translate animal vaccine dose-responses to human vaccination. Thus, each vaccine development group collates the relevant literature, and their own data, to determine how to design initial animal or human dose-response 
studies. Unfortunately, recent evidence suggests that this empirical method of dose selection has, in part, led to suboptimal dose identification in humans for diseases, such as yellow fever, meningitis and malaria [3-6].

Recently developed mathematical modelling methods, referred to as immunostimulation/immunodynamic (IS/ID) modelling, attempts to address these issues [7-10]. IS/ID modelling was developed to address the lack of quantitative methods in vaccine development [11]. The aim of IS/ID is to translate pharmacokinetic/pharmacodynamic (PK/PD) methodology to vaccine development, and preliminary IS/ID modelling has shown promise in accelerating vaccine dosing decisions. Modelling of the dose-response curve and cross-species translation of tuberculosis vaccine dosing data have predicted a lower human dose than previously tested [7,9], and showed that antibody response against human parainfluenza virus may be maximised by an intermediate dose [12]. To inform future IS/ID modelling, dose-response data must be collated. However, these data can also provide valuable insight into study designs that are currently used to explore vaccine dose-response, as understanding the scope of previous dose-ranging trials may be of use in determining the cause of suboptimal dosing.

Adenovirus vectored vaccines have been widely investigated for their ability to induce antibody and $\mathrm{T}$ cell responses against infectious diseases and cancers [13]. However, the dose-response for adenoviral vectored vaccines has not yet been systematically investigated. In this systematic review, we aim to explore and collate available adenoviral dose-response data for the purpose of informing adenoviral dosing towards safer and more effective vaccination. Our objectives were to:

1. Assess the number of available papers, including adenoviral dose-response studies, and the distribution of host species and adenoviral serotypes within these papers.

2. Assess which immunological responses dose-response data were available.

3. Assess the dosing strategies used in adenoviral dose-ranging studies, including number and magnitude of dose levels.

This systematic review should help inform adenoviral vaccine developers in choosing dose amounts for first-in-human trials. The collated data on dose-response, and replicating incompetent adenovirus-based vaccines, will also be used to inform IS/ID modelling studies for vaccine dose optimisation.

\section{Materials and Methods}

The study protocol was registered in PROSPERO (CRD42017080183).

\subsection{Study Types, Study Design, Population, Intervention and Outcome Measures}

Papers on clinical trials and in-vivo pre-clinical studies, that presented data from adenovirus vector-induced immunogenicity, were included in the review. These could include data from humans and animals of any age, sex and genetic background who received adenoviral vectored vaccines administered intramuscularly or subcutaneously. We did not assess study design aspects, such as methods of randomisation or use of control groups. The primary outcome measures were humoral and cellular immunity.

\subsection{Search Strategy}

The MEDLINE (PubMed) database was searched from inception to 27 November 2018. The search was limited to papers published in English and included terms relating to the following concepts: Adenovirus-vectored vaccines, immunogenicity, and dose-response (Appendix A, Criteria A1).

\subsection{Paper Selection (Inclusion/Exclusion Criteria)}

A three-stage screening process was used to systematically screen retrieved references and assess whether they met the inclusion criteria. Papers were first screened by title then by abstract before a full-text screen was conducted (Appendix A, Figure A1). 
We included papers that presented data from studies with immunological response at three or more dose levels of an adenoviral vectored vaccine. We included papers that captured CD4+/CD8+ T-cell response, as measured by cytokine release using either ELISPOT or multiparameter flow cytometry and/or humoral responses, including binding and neutralising antibody titres against the vector and antigen. Exclusion criteria were chosen to minimize the probability of response being altered by a non-dosal effect, for example excluding cancer models and prime-boost paradigm vaccination (Appendix A, Figure A2).

\subsection{Data Extraction}

Using a pre-designed data extraction spreadsheet, information relating to study characteristics were extracted from studies that met the inclusion criteria. Numerical data from figures were extracted using GraphClick version 2.9.2 (Arizona Software, Los Angeles, CA, USA). Papers could contain data from multiple dose-response studies, and these studies may vary in adenoviral serotype, route of administration, host species, or disease.

\subsection{Assessment of Methodological Quality}

Bias was controlled for by having two individuals participate in the original search, and on abstract review. A review of 10 articles known to be relevant was conducted, to evaluate the degree of completeness. No statistical methods were performed to assess publication bias.

\subsection{Comparing Doses}

Three different units of measurement of dose were used in the extracted studies; viral particles (VPs), particle units (PUs), or plaque forming units (PFUs). Doses measured in VPs and PUs were considered equivalent as they both measure the number of physical viral particles [14]. PFUs were considered a separate outcome, as the ratio of VPs/PUs to PFUs were not constant in adenoviral vaccines studies [15].

\section{Results}

3.1. Objective 1: Assess the Number of Available Papers Including Adenoviral Dose-Response Studies, and the Distribution of Host Species and Adenoviral Serotypes within These Papers

Following removal of duplicate entries, 2787 references remained and were screened by title. 581 references were screened by abstract and 300 were screened by full text. After evaluation of the full text, 265 of the papers were excluded. Therefore, 35 papers were included in this review [16-50]. The majority of papers contained studies conducted in mice (60\%), followed by humans (26\%) (Table 1). Although, it is likely that many studies may have been carried out by industry using the same construct in mice and humans, the number of published studies using the same adenoviral strain, route and antigen insert across different species was limited.

Table 1. The number of papers that included dose-response studies for each host species identified in the review.

\begin{tabular}{lll}
\hline Number of Papers (\%) & Host & Paper References \\
\hline $21(60 \%)$ & Mouse & {$[18,22,24-26,29,32-36,39-41,43-45,47-50]$} \\
$9(26 \%)$ & Human & {$[16,17,19-21,23,27,28,30]$} \\
$2(6 \%)$ & Monkey & {$[38,42]$} \\
$2(6 \%)$ & Rat & {$[37,45]$} \\
$1(3 \%)$ & Rabbit & {$[31]$} \\
$1(3 \%)$ & Cattle & {$[46]$} \\
\hline
\end{tabular}


Out of all the adenoviral serotypes, the most common was human adenovirus 5 (46\%), followed by human adenovirus 35 (26\%) (Table 2$)$. The route of administration was more frequently intramuscular $(84 \%)$ than subcutaneous $(16 \%)$.

Table 2. The number and percentage of papers that included dose-response data for each adenovirus serotype.

\begin{tabular}{ll}
\hline Human & Non-Human Primates \\
\hline Ad5 $(16,46 \%)[22,24,25,29,31,33,34,38,39,42-46,49,50]$ & ChAd63 $(3,9 \%)[24,30,43]$ \\
Ad35 $(9,26 \%)[19,21,23,24,26,28,35,36,39]$ & ChAd3 $(3,9 \%)[16,17,24]$ \\
$\operatorname{Ad} 26(4,11 \%)[26,27,32,37]$ & AdC6 $(1,3 \%)[41]$ \\
Ad6 $(2,6 \%)[38,47]$ & $\operatorname{AdC7}(1,3 \%)[40]$ \\
Ad28 $(1,3 \%)[24]$ & sAd11 $(1,3 \%)[24]$ \\
& sAd16 $(1,3 \%)[24]$ \\
& sAdv-36 $(1,3 \%)[48]$ \\
& ChAdOx1 $(1,3 \%)[20]$ \\
\hline
\end{tabular}

3.2. Objective 2: Assess for Which Immunological Responses Dose-Response Data Were Available

The immunogenicity data recorded also varied widely among the published studies, including antibody responses (both binding and neutralizing), T cell ELISpot data, and CD4+ and CD8+ T cell responses by intracellular cytokine staining. The majority of papers (51\%) included studies of antibody dose-response. (Table 3).

Table 3. The number and percentage of papers that included dose-response data for each immunological response type.

\begin{tabular}{lll}
\hline Number of Papers (\%) & Response Type & Paper References \\
\hline $18(51 \%)$ & Antibody & {$[16,17,20-23,25-28,31,33,36,39,40,42,45,48]$} \\
$12(34 \%)$ & T cell count & {$[16,20,21,26-28,30,32,36,38,42,47]$} \\
$12(34 \%)$ & CD8+ T cell count & {$[19,22,24,32,34-36,38,39,48-50]$} \\
$11(31 \%)$ & Virus Neutralisation Titre & {$[22,25,27,29,30,34,36,37,43,44,46]$} \\
$4(12 \%)$ & CD4+ T cell count & {$[19,32,35,38]$} \\
$3(9 \%)$ & CD8+ T Cell, IFN-y+ Percentage & {$[19,21,41]$} \\
$3(9 \%)$ & CD4+ T Cell, IFN-y+ Percentage & {$[19,21]$} \\
$2(6 \%)$ & CD4+ T Cell, TNF-a+ Percentage & {$[19,21]$} \\
$2(6 \%)$ & CD8+ T Cell, TNF-a+ Percentage & {$[21]$} \\
$2(6 \%)$ & CD4+ T Cell, IL-2+ Percentage & {$[19,21]$} \\
$2(6 \%)$ & CD8+ T Cell, Il-2+ Percentage & {$[21]$} \\
$1(3 \%)$ & CD4+ T Cell, Il-17+ Percentage & {$[19]$} \\
\hline
\end{tabular}

3.3. Objective 3: Assess the Dosing Strategies Used in Adenoviral Dose-Ranging Studies, Including Number and Magnitude of Dose Levels

\subsubsection{Number of Dose Levels}

The majority of papers $(60 \%)$ included studies with three dose levels, which was the minimum number of dose levels for a study to be included; $23 \%$ included four dose levels, and $20 \%$ included five or more levels (Table 4).

Table 4. The number and percentage of papers containing studies at each number of dosing levels.

\begin{tabular}{lll}
\hline Number of Papers (\%) & Number of Dose Levels & Paper References \\
\hline $21(60 \%)$ & 3 & {$[17,19,22,24,25,27-30,32,34,35,37,38,40,42,44,46,48,49]$} \\
$8(23 \%)$ & 4 & {$[16,20,21,23,26,36,40,43]$} \\
$5(14 \%)$ & 5 & {$[18,33,39,41,45]$} \\
$1(3 \%)$ & 6 & {$[31]$} \\
$1(3 \%)$ & 7 & {$[47]$} \\
\hline
\end{tabular}




\subsubsection{Magnitude of Dose Levels}

For VP/PU, the geometric mean human dose was $1.6 \times 10^{10}$ (range $5 \times 10^{8}-2 \times 10^{11}$ ) (Figure 1a). No human dose-response studies were measured in PFU. In VP, the geometric mean mouse dose was $4.9 \times 10^{7}$, (range $5 \times 10^{1}-5 \times 10^{11}$ ) (Figure $1 \mathrm{~b}$ ). The mean human dose was therefore approximately $3.2 \times 10^{2}$ times larger than the mean mouse dose. Four mouse dose-response studies measured dose in PFU, with doses ranging between $1 \times 10^{4}$ and $1 \times 10^{9}$ PFU. Details on the magnitude of dose levels are found in Appendix A, Figure A2.

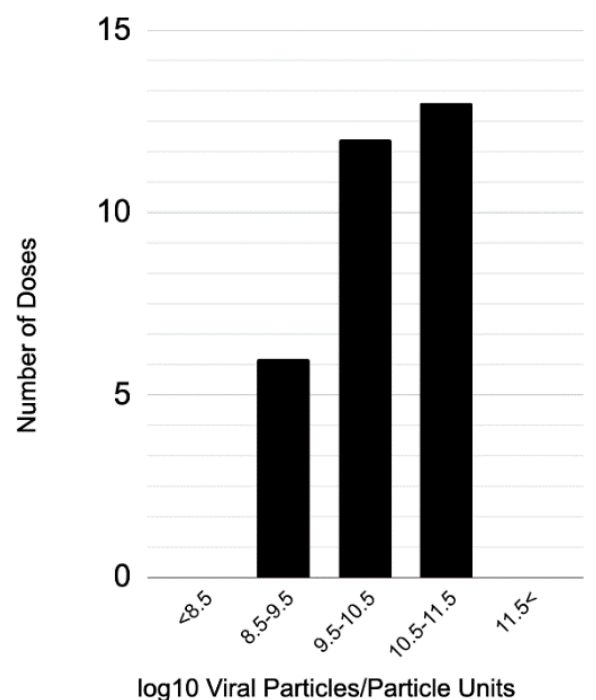

(a)

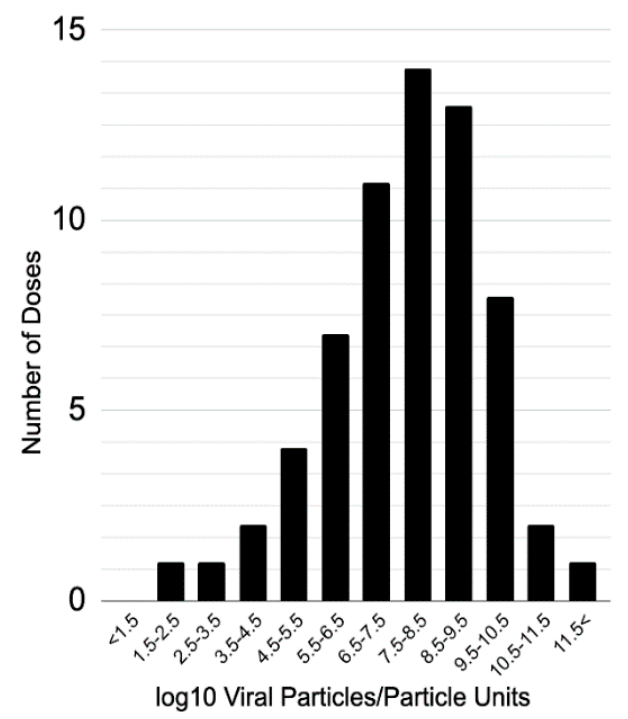

(b)

Figure 1. Frequency of dose magnitudes for all adenoviral vector vaccine dose-response studies with doses measured in VP/PFU in (a) humans and (b) mice.

\section{Discussion}

In this review we aimed to collate data on adenovirus-based vaccines in preparation for mathematical modelling to characterize the dose-response curve by host species, serogroup of the adenovirus or route of administration. After screening, 35 papers were extracted that provided dose-response immunogenicity data following intramuscularly or subcutaneously administered adenovirus vectors in animals and humans. Data were primarily from mouse and human studies, and included multiple different response types. From the adenoviral dose-response papers considered, studies typically used three dose levels, with the average human dose being two orders of magnitude larger than the average mouse dose. There were unfortunately very few comparator trials in which the same vaccine was used in human and animal models, and much of the pre-clinical data from larger industry companies are unlikely to have been published.

This review represents the first attempt to collate vaccine dose-response data, which has not yet been done for adenoviral vectored or non-adenovirus vectored vaccines. The review found that dose-response data existed for a wide range of immunological responses, both humoral and cellular. This suggests that published dose-response data may exist for many important correlates of protection. The broad spectrum of available data will be used to inform an IS/ID modelling study on adenoviral dose-response curve shape. However, the majority of studies used too few doses to allow for true dose response relationships to be clearly established, and thus, the majority of studies conducted are not sufficient to allow the authors to clearly justify their dose selection. To establish a true sigmoidal curve fit, at least five data points are needed to accurately model the response.

Whilst this review was able to identify 35 papers that may be useful in understanding adenoviral vectored vaccine dose-response behaviour, there are factors that may limit the utility of the collated 
data. Firstly, it is likely that there exist vaccine dose-response studies that have not been published [51]. In order to predict dose-response in humans from animals for future vaccines, dose-response data from an existing vaccine in multiple species is required. The unavailability of these data may hinder attempts to develop an allometric scaling approach, therefore publishing of both clinical and pre-clinical dose-response studies is of great importance. Secondly, most of the doses were measured in viral particles, which may be a sub-optimal measure [52] as the infectious ratio, the number of viral particles per infectious unit, can vary between vaccines [15]. Therefore, the use of VP in measuring vaccine dose limits the comparisons in dose between different vaccines. Finally, when applying IS/ID modelling to define the dose-response curve, it is also possible that, whilst three dosing levels may be sufficient to theoretically define simple curves like a sigmoid function, this may not be a large enough number of doses to determine dose-response behaviour with an appropriate degree of certainty.

The strategies used to optimise vaccine dosing are likely to be suboptimal. There might exist mathematical descriptions of dose-response that are informative when choosing the various doses to use for a given construct in a given species which have not yet been identified. Indeed, both Darrah and Belovsky have shown that the highest dose was not the most effective dose for adenoviral vectored vaccination against Leishmania and non-adenovirus vectored vaccination against HIV [53,54], and yet the bias to choose the maximum safe dose remains among most vaccine developers.

New methods of vaccine dose optimisation need to be developed. Understanding adenoviral vaccine dose-response may be able to be achieved through reviewing and comparing historical dose-response data and combining these with mathematical modelling methods. This may aid in ensuring that the optimal dose for protection and safety is identified, while minimising the number of human and animal participants required to decide that dose.

Author Contributions: Conceptualization, S.A., S.R. and T.E.; methodology, S.A., J.B., S.R. and T.E.; software, S.A. and S.R.; validation, J.B., S.R. and R.W.; formal analysis, S.A. and J.B.; investigation, S.A. and J.B.; resources, T.E.; data curation, S.A. and J.B.; writing-original draft preparation, S.A. and J.B.; writing —review and editing, S.A., R.W. and T.E.; visualization, S.A. and J.B.; supervision, R.W. and T.E.; project administration, S.R; funding acquisition, T.E. All authors have read and agreed to the published version of the manuscript.

Funding: This research was funded by Vaccitech Ltd. This work was supported by BBSRC LiDO PHD studentship (J.B.). R.G.W. is funded by the UK Medical Research Council (MRC) and the UK Department for International Development (DFID) under the MRC/DFID Concordat agreement that is also part of the EDCTP2 programme supported by the European Union (MR/P002404/1), The Bill and Melinda Gates Foundation (TB Modelling and Analysis Consortium: OPP1084276/OPP1135288, CORTIS: OPP1137034/OPP1151915, Vaccines: OPP1160830), UNITAID (4214-LSHTM-Sept15; PO 8477-0-600), and ESRC (ES/P008011/1).

Conflicts of Interest: This work is partially funded by Vaccitech, a company that is developing novel adenoviral vector vaccines using the vectors ChAdOx1 and ChAdOx2.

\section{Appendix A}

Criteria A1. Search Terms, PubMed

\begin{tabular}{llc}
\hline Strategy & PUBMED Search & $\#$ \\
\hline Concept 1 Adenovirus & $\begin{array}{l}\text { adenovirus OR adenoviral OR adenovector OR adenovectors OR adenoviridae } \\
\text { dose OR doses OR dosage OR dosages OR dosing OR dosed OR dose response }\end{array}$ & 1 \\
Concept 2 Dose & $\begin{array}{l}\text { OR dose-response OR dose responses OR dose-responses OR dose response } \\
\text { relationship OR dose-response relationship }\end{array}$ & 2 \\
& $\begin{array}{l}\text { immunity OR immune OR immune-response OR immune response OR } \\
\text { immune responses OR immune-responses OR immunostimulation OR }\end{array}$ \\
Concept 3 Immune & $\begin{array}{l}\text { immunodynamic OR immunodynamics OR immunisation OR immunisations } \\
\text { response }\end{array}$ & $\begin{array}{l}\text { OR immunization OR immunizations OR immunise OR immunises OR } \\
\text { immunize OR immunizes OR immunised OR immunized OR immunising OR }\end{array}$ \\
& immunizing OR immunogenecity OR immunogenic OR immunology & \\
Combine with AND & \#1 AND \#2 AND \#3 & \\
Add filter: & Humans, Other Animals, English & \\
\hline
\end{tabular}




\section{Criteria A2. Exclusion Criteria}

A study was excluded if it; (a) was a gene transfer study, (b) was conducted in cancer models, (c) presented no immunological readouts, (d) used replication-competent adenovirus, (e) did not administer adenovirus via an intramuscular or subcutaneous route, (f) used adenovirus as a boost in a heterologous prime-boost vaccination regimen, $(\mathrm{g})$ used adenovirus as a prime, in a heterologous prime-boost regimen, and did not report on immunological parameters post-prime and pre-boost, (h) presented a homologous dosing regimen with no reported immunological parameters after the initial dose, (i) only reported on immune parameters following a disease challenge, (j) co-administered an adjuvant, administered an adjuvant prior to adenovirus delivery or used an ad-juvant-encoded adenovirus vector, $(\mathrm{k})$ only reported on pulmonary immunity to the adenovirus (l) presented only data on gene expression, (m) used a sample size of less than five mice per group, or less than three for non-human primates, (n) presented in-vitro derived data, or (o) was a systematic review or meta-analysis.
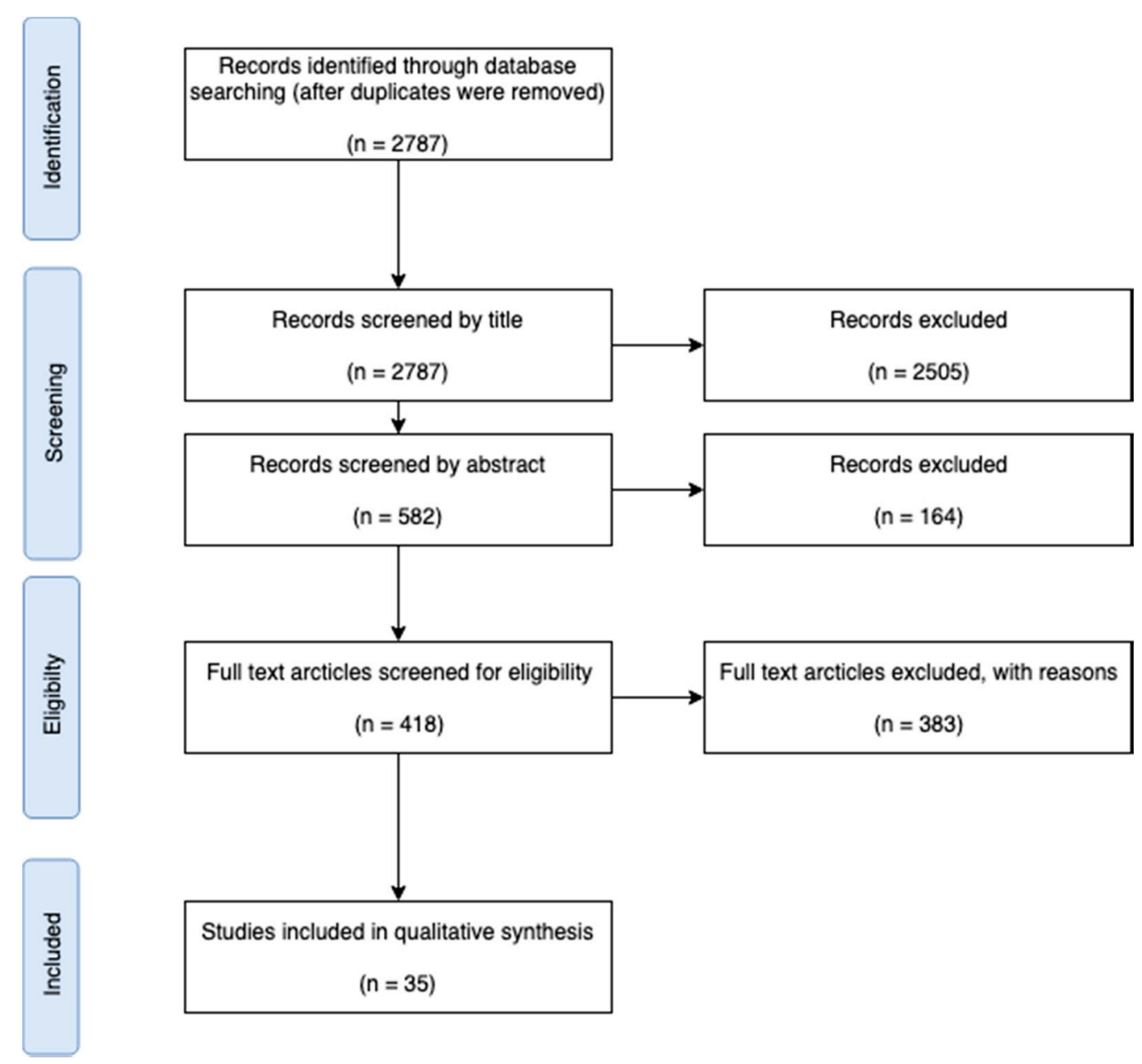

Figure A1. Flow chart diagram of the search and screening strategy. 


\begin{tabular}{|c|c|c|c|c|c|c|c|c|c|c|}
\hline Paper & Ref & Species & Dose 1 & Dose 2 & Dose 3 & Dose 4 & Dose 5 & Dose 6 & Dose 7 & Units \\
\hline Antrobus, 2014 & 20 & Human & $5.00 \mathrm{E}+08$ & $5.00 E+09$ & $2.50 \mathrm{E}+10$ & $5.00 \mathrm{E}+10$ & & & & VP \\
\hline Baden, 2013 & 27 & Human & $1.00 \mathrm{E}+09$ & $1.00 E+10$ & $1.00 \mathrm{E}+11$ & & & & & VP \\
\hline Capone, 2006 & 38 & Monkey & $1.00 \mathrm{E}+08$ & $1.00 \mathrm{E}+10$ & $1.00 \mathrm{E}+11$ & & & & & VP \\
\hline Casimiro, 2003 & 42 & Monkey & $1.00 \mathrm{E}+07$ & $1.00 E+09$ & $1.00 \mathrm{E}+11$ & & & & & VP \\
\hline Creech, 2013 & 23 & Human & $1.00 \mathrm{E}+09$ & $1.00 E+10$ & $5.00 \mathrm{E}+10$ & $1.00 \mathrm{E}+11$ & & & & VP \\
\hline Eloit, 1995 & 45 & Mouse & $1.00 \mathrm{E}+05$ & $1.00 \mathrm{E}+06$ & $1.00 \mathrm{E}+07$ & $1.00 \mathrm{E}+08$ & $1.00 \mathrm{E}+09$ & & & VP \\
\hline Eloit, 1995 & 45 & Rat & $1.00 \mathrm{E}+05$ & $1.00 E+06$ & $1.00 \mathrm{E}+07$ & $1.00 \mathrm{E}+08$ & $1.00 E+09$ & & & VP \\
\hline Ewer, 2016 & 17 & Human & $1.00 \mathrm{E}+10$ & $2.50 \mathrm{E}+10$ & $5.00 \mathrm{E}+10$ & & & & & VP \\
\hline Fonseca, 2017 & 48 & Mouse & $1.00 \mathrm{E}+06$ & $1.00 \mathrm{E}+07$ & $1.00 \mathrm{E}+10$ & & & & & VP \\
\hline Hashimoto, 2005 & 40 & Mouse & $1.00 \mathrm{E}+08$ & $1.00 E+09$ & $1.00 \mathrm{E}+10$ & $1.00 \mathrm{E}+11$ & & & & PU \\
\hline Kagina, 2014 & 19 & Human & $1.50 \mathrm{E}+09$ & $1.50 E+10$ & $1.00 \mathrm{E}+11$ & & & & & VP \\
\hline Keefer, 2012 & 28 & Human & $2.00 \mathrm{E}+09$ & $2.00 \mathrm{E}+10$ & $2.00 \mathrm{E}+11$ & & & & & VP \\
\hline Nazerai, 2016 & 49 & Mouse & $2.00 \mathrm{E}+05$ & $2.00 \mathrm{E}+06$ & $2.00 \mathrm{E}+07$ & & & & & PFU \\
\hline Neilan, 2018 & 46 & Cattle & $3.13 \mathrm{E}+09$ & $1.25 \mathrm{E}+10$ & $5.00 \mathrm{E}+10$ & & & & & PU \\
\hline O. J. a. E. Ophorst, 2006 & 39 & Mouse & $1.00 \mathrm{E}+06$ & $1.00 \mathrm{E}+07$ & $1.00 \mathrm{E}+08$ & $1.00 \mathrm{E}+09$ & $1.00 \mathrm{E}+10$ & & & VP \\
\hline O. J. A. E. Ophorst, 2007 & 36 & Mouse & $1.00 \mathrm{E}+07$ & $1.00 \mathrm{E}+08$ & $1.00 \mathrm{E}+09$ & $1.00 \mathrm{E}+10$ & & & & VP \\
\hline O'Hara, 2012 & 30 & Human & $1.00 \mathrm{E}+10$ & $5.00 \mathrm{E}+10$ & $2.00 \mathrm{E}+11$ & & & & & VP \\
\hline Ondondo, 2014 & 18 & Mouse & $1.00 \mathrm{E}+05$ & $1.00 \mathrm{E}+06$ & $1.00 \mathrm{E}+07$ & $1.00 \mathrm{E}+08$ & $1.00 \mathrm{E}+09$ & & & VP \\
\hline Ouédraogo, 2013 & 21 & Human & $1.00 \mathrm{E}+09$ & $1.00 \mathrm{E}+10$ & $5.00 \mathrm{E}+10$ & $1.00 \mathrm{E}+11$ & & & & VP \\
\hline Pandey, 2012 & 29 & Mouse & $1.00 \mathrm{E}+07$ & $1.00 \mathrm{E}+08$ & $1.00 \mathrm{E}+09$ & & & & & PFU \\
\hline Penaloza-MacMaster, 2016 & 50 & Mouse & $1.00 \mathrm{E}+08$ & $1.00 \mathrm{E}+09$ & $1.00 \mathrm{E}+10$ & & & & & VP \\
\hline Pinto, 2003 & 41 & Mouse & $5.00 \mathrm{E}+07$ & $5.00 \mathrm{E}+08$ & $5.00 \mathrm{E}+09$ & $5.00 \mathrm{E}+10$ & $5.00 \mathrm{E}+11$ & & & VP \\
\hline Quinn, 2013 & 24 & Mouse & $1.00 \mathrm{E}+07$ & $1.00 \mathrm{E}+08$ & $1.00 \mathrm{E}+09$ & & & & & PU \\
\hline Rhee, 2010 & 32 & Mouse & $3.00 \mathrm{E}+07$ & $3.00 E+08$ & $3.00 \mathrm{E}+09$ & & & & & VP \\
\hline Richardson, 2009 & 34 & Mouse & $1.00 \mathrm{E}+04$ & $1.00 \mathrm{E}+05$ & $1.00 \mathrm{E}+06$ & & & & & VP \\
\hline Rodríguez, 2008 & 35 & Mouse & $1.00 \mathrm{E}+08$ & $1.00 E+09$ & $1.00 \mathrm{E}+10$ & & & & & VP \\
\hline Steitz, 2010 & 33 & Mouse & $5.00 \mathrm{E}+01$ & $5.00 \mathrm{E}+02$ & $5.00 \mathrm{E}+03$ & $5.00 \mathrm{E}+04$ & $5.00 \mathrm{E}+05$ & & & VP \\
\hline Sun, 2011 & 31 & Rabbit & $1.00 \mathrm{E}+04$ & $1.50 E+05$ & $1.25 \mathrm{E}+05$ & $2.50 \mathrm{E}+05$ & $5.00 \mathrm{E}+05$ & $1.00 \mathrm{E}+06$ & & TCID50 \\
\hline Tang, 2017 & 47 & Mouse & $1.00 \mathrm{E}+06$ & $4.00 E+06$ & $1.00 \mathrm{E}+07$ & $4.00 \mathrm{E}+07$ & $1.00 \mathrm{E}+08$ & $4.00 \mathrm{E}+08$ & $1.00 \mathrm{E}+09$ & VP \\
\hline Tapia, 2016 & 16 & Human & $1.00 \mathrm{E}+10$ & $2.50 \mathrm{E}+10$ & $5.00 \mathrm{E}+10$ & $1.00 \mathrm{E}+11$ & & & & PU \\
\hline Vemula, 2013 & 22 & Mouse & $2.00 \mathrm{E}+07$ & $1.00 \mathrm{E}+08$ & $5.00 \mathrm{E}+08$ & & & & & VP \\
\hline Widjojoatmodjo, 2015 & 37 & Rat & $1.00 \mathrm{E}+06$ & $1.00 \mathrm{E}+08$ & $1.00 \mathrm{E}+09$ & & & & & VP \\
\hline Z. Q. Xiang, 1996 & 44 & Mouse & $1.00 \mathrm{E}+02$ & $1.00 E+03$ & $1.00 \mathrm{E}+04$ & & & & & PFU \\
\hline Z. Q. Xiang, 1996 & 44 & Mouse & $2.00 \mathrm{E}+04$ & $2.00 E+05$ & $2.00 \mathrm{E}+06$ & & & & & PFU \\
\hline Z. Xiang, 2002 & 43 & Mouse & $1.00 \mathrm{E}+04$ & $1.00 \mathrm{E}+05$ & $1.00 \mathrm{E}+06$ & $1.00 \mathrm{E}+07$ & & & & PFU \\
\hline Zahn, 2012 & 26 & Mouse & $1.00 \mathrm{E}+07$ & $1.00 \mathrm{E}+08$ & $1.00 \mathrm{E}+09$ & $1.00 \mathrm{E}+10$ & & & & VP \\
\hline Zhou, 2013 & 25 & Mouse & $5.00 \mathrm{E}+06$ & $5.00 \mathrm{E}+07$ & $1.00 \mathrm{E}+08$ & & & & & PFU \\
\hline
\end{tabular}

Figure A2. Dose magnitudes for the collected studies, including the name of the paper, the host species, and the unit used to quantify dose.

\section{References}

1. Davis, H.L. Novel vaccines and adjuvant systems: The utility of animal models for predicting immunogenicity in humans. Hum. Vaccines 2008, 4, 246-250. [CrossRef] [PubMed]

2. Nair, A.B.; Jacob, S. A simple practice guide for dose conversion between animals and human. J. Basic Clin. Pharm. 2016, 7, 27-31. [CrossRef] [PubMed]

3. Campi-Azevedo, A.C.; de Almeida Estevam, P.; Coelho-dos-Reis, J.G.; Peruhype-Magalhães, V.; Villela-Rezende, G.; Quaresma, P.F.; de Lourdes Sousa Maia, M.; Farias, R.H.G.; Camacho, L.A.B.; da Silva Freire, M.; et al. Subdoses of 17DD yellow fever vaccine elicit equivalent virological/immunological kinetics timeline. BMC Infect. Dis. 2014, 14, 391. [CrossRef] [PubMed]

4. Guerin, P.J.; Naess, L.M.; Fogg, C.; Rosenqvist, E.; Pinoges, L.; Bajunirwe, F.; Nabasumba, C.; Borrow, R.; Frøholm, L.O.; Ghabri, S.; et al. Immunogenicity of fractional doses of tetravalent a/c/y/w135 meningococcal polysaccharide vaccine: Results from a randomized non-inferiority controlled trial in Uganda. PLoS ONE Negl. Trop. Dis. 2008, 2, e342. [CrossRef] 
5. Martins, R.M.; Maia, M.D.L.S.; Farias, R.H.G.; Camacho, L.A.B.; Freire, M.S.; Galler, R.; Yamamura, A.M.Y.; Almeida, L.F.C.; Lima, S.M.B.; Nogueira, R.M.R.; et al. 17DD yellow fever vaccine: A double blind, randomized clinical trial of immunogenicity and safety on a dose-response study. Hum. Vaccines Immunother. 2013, 9, 879-888. [CrossRef] [PubMed]

6. $\quad$ Regules, J.A.; Cicatelli, S.B.; Bennett, J.W.; Paolino, K.M.; Twomey, P.S.; Moon, J.E.; Kathcart, A.K.; Hauns, K.D.; Komisar, J.L.; Qabar, A.N.; et al. Fractional Third and Fourth Dose of RTS,S/AS01 Malaria Candidate Vaccine: A Phase 2a Controlled Human Malaria Parasite Infection and Immunogenicity Study. J. Infect. Dis. 2016, 214, 762-771. [CrossRef]

7. Rhodes, S.J.; Zelmer, A.; Knight, G.M.; Prabowo, S.A.; Stockdale, L.; Evans, T.G.; Lindenstrøm, T.; White, R.G.; Fletcher, H. The TB vaccine H56 + IC31 dose-response curve is peaked not saturating: Data generation for new mathematical modelling methods to inform vaccine dose decisions. Vaccine 2016, 34, 6285-6291. [CrossRef]

8. Rhodes, S.J.; Knight, G.M.; Kirschner, D.E.; White, R.G.; Evans, T.G. Dose finding for new vaccines: The role for immunostimulation/immunodynamic modelling. arXiv 2018, arXiv:1811.04024. [CrossRef]

9. Rhodes, S.J.; Guedj, J.; Fletcher, H.A.; Lindenstrøm, T.; Scriba, T.J.; Evans, T.G.; Knight, G.M.; White, R.G. Using vaccine Immunostimulation/Immunodynamic modelling methods to inform vaccine dose decision-making. Npj Vaccines 2018, 3, 36. [CrossRef]

10. Rhodes, S.J.; Sarfas, C.; Knight, G.M.; White, A.; Pathan, A.A.; McShane, H.; Evans, T.G.; Fletcher, H.; Sharpe, S.; White, R.G. Using Data from Macaques to Predict Gamma Interferon Responses after Mycobacterium bovis BCG Vaccination in Humans: A Proof-of-Concept Study of Immunostimulation/Immunodynamic Modeling Methods. Clin. Vaccine Immunol. 2017, 24. [CrossRef]

11. Rhodes, S.J.; Knight, G.M.; Kirschner, D.E.; White, R.G.; Evans, T.G. Dose finding for new vaccines: The role for immunostimulation/immunodynamic modelling. J. Theor. Biol. 2019, 465, 51-55. [CrossRef] [PubMed]

12. Handel, A.; Li, Y.; McKay, B.; Pawelek, K.A.; Zarnitsyna, V.; Antia, R. Exploring the impact of inoculum dose on host immunity and morbidity to inform model-based vaccine design. PLoS ONE Comput. Biol. 2018, 14, e1006505. [CrossRef] [PubMed]

13. Zhang, C.; Zhou, D. Adenoviral vector-based strategies against infectious disease and cancer. Hum. Vaccines Immunother. 2016, 12, 2064-2074. [CrossRef] [PubMed]

14. Sheets, R.L.; Stein, J.; Bailer, R.T.; Koup, R.A.; Andrews, C.; Nason, M.; He, B.; Koo, E.; Trotter, H.; Duffy, C.; et al. Biodistribution and Toxicological Safety of Adenovirus Type 5 and Type 35 Vectored Vaccines Against Human Immunodeficiency Virus-1 (HIV-1), Ebola, or Marburg Are Similar Despite Differing Adenovirus Serotype Vector, Manufacturer's Construct, or Gene Inserts. J. Immunotoxicol. 2008, 5, 315-335. [PubMed]

15. Klasse, P.J. Molecular Determinants of the Ratio of Inert to Infectious Virus Particles. Prog. Mol. Biol. Transl. Sci. 2015, 129, 285-326. [PubMed]

16. Tapia, M.D.; Sow, S.O.; Lyke, K.E.; Haidara, F.C.; Diallo, F.; Doumbia, M.; Traore, A.; Coulibaly, F.; Kodio, M.; Onwuchekwa, U.; et al. Use of ChAd3-EBO-Z Ebola virus vaccine in Malian and US adults, and boosting of Malian adults with MVA-BN-Filo: A phase 1, single-blind, randomised trial, a phase 1b, open-label and double-blind, dose-escalation trial, and a nested, randomised, double-blind, placebo-controlled trial. Lancet Infect. Dis. 2016, 16, 31-42.

17. Ewer, K.; Rampling, T.; Venkatraman, N.; Bowyer, G.; Wright, D.; Lambe, T.; Imoukhuede, E.B.; Payne, R.; Fehling, S.K.; Strecker, T.; et al. A Monovalent Chimpanzee Adenovirus Ebola Vaccine Boosted with MVA. N. Engl. J. Med. 2016, 374, 1635-1646. [CrossRef]

18. Ondondo, B.; Abdul-Jawad, S.; Bridgeman, A.; Hanke, T. Characterization of T-Cell Responses to Conserved Regions of the HIV-1 Proteome in BALB/c Mice. Clin. Vaccine Immunol. CVI 2014, 21, 1565-1572. [CrossRef]

19. Kagina, B.M.N.; Tameris, M.D.; Geldenhuys, H.; Hatherill, M.; Abel, B.; Hussey, G.D.; Scriba, T.J.; Mahomed, H.; Sadoff, J.C.; Hanekom, W.A.; et al. The novel tuberculosis vaccine, AERAS-402, is safe in healthy infants previously vaccinated with BCG, and induces dose-dependent CD4 and CD8T cell responses. Vaccine 2014, 32, 5908-5917. [CrossRef]

20. Antrobus, R.D.; Coughlan, L.; Berthoud, T.K.; Dicks, M.D.; Hill, A.V.; Lambe, T.; Gilbert, S.C. Clinical assessment of a novel recombinant simian adenovirus $\mathrm{ChAdOx} 1$ as a vectored vaccine expressing conserved Influenza A antigens. Mol. Ther. J. Am. Soc. Gene Ther. 2014, 22, 668-674. [CrossRef] 
21. Ouédraogo, A.; Tiono, A.B.; Kargougou, D.; Yaro, J.B.; Ouédraogo, E.; Kaboré, Y.; Kangoye, D.; Bougouma, E.C.; Gansane, A.; Henri, N.; et al. A phase 1b randomized, controlled, double-blinded dosage-escalation trial to evaluate the safety, reactogenicity and immunogenicity of an adenovirus type 35 based circumsporozoite malaria vaccine in Burkinabe healthy adults 18 to 45 years of age. PLoS ONE 2013, 8, e78679. [CrossRef] [PubMed]

22. Vemula, S.V.; Amen, O.; Katz, J.M.; Donis, R.; Sambhara, S.; Mittal, S.K. Beta-defensin 2 enhances immunogenicity and protection of an adenovirus-based H5N1 influenza vaccine at an early time. Virus Res. 2013, 178, 398-403. [CrossRef] [PubMed]

23. Creech, C.B.; Dekker, C.L.; Ho, D.; Phillips, S.; Mackey, S.; Murray-Krezan, C.; Grazia Pau, M.; Hendriks, J.; Brown, V.; Dally, L.G.; et al. Randomized, placebo-controlled trial to assess the safety and immunogenicity of an adenovirus type 35-based circumsporozoite malaria vaccine in healthy adults. Hum. Vaccines Immunother. 2013, 9, 2548-2557. [CrossRef] [PubMed]

24. Quinn, K.M.; Da Costa, A.; Yamamoto, A.; Berry, D.; Lindsay, R.W.B.; Darrah, P.A.; Wang, L.; Cheng, C.; Kong, W.-P.; Gall, J.G.D.; et al. Comparative analysis of the magnitude, quality, phenotype, and protective capacity of simian immunodeficiency virus gag-specific CD8+ T cells following human-, simian-, and chimpanzee-derived recombinant adenoviral vector immunization. J. Immunol. Baltim. Md 1950 2013, 190, 2720-2735. [CrossRef] [PubMed]

25. Zhou, G.; Wang, H.; Wang, F.; Yu, L. Recombinant adenovirus expressing type Asia1 foot-and-mouth disease virus capsid proteins induces protective immunity against homologous virus challenge in mice. Res. Vet. Sci. 2013, 94, 796-802. [CrossRef]

26. Zahn, R.; Gillisen, G.; Roos, A.; Koning, M.; van der Helm, E.; Spek, D.; Weijtens, M.; Grazia Pau, M.; Radošević, K.; Weverling, G.J.; et al. Ad35 and ad26 vaccine vectors induce potent and cross-reactive antibody and T-cell responses to multiple filovirus species. PLOS ONE 2012, 7, e44115. [CrossRef]

27. Baden, L.R.; Walsh, S.R.; Seaman, M.S.; Tucker, R.P.; Krause, K.H.; Patel, A.; Johnson, J.A.; Kleinjan, J.; Yanosick, K.E.; Perry, J.; et al. First-in-human evaluation of the safety and immunogenicity of a recombinant adenovirus serotype 26 HIV-1 Env vaccine (IPCAVD 001). J. Infect. Dis. 2013, 207, 240-247. [CrossRef]

28. Keefer, M.C.; Gilmour, J.; Hayes, P.; Gill, D.; Kopycinski, J.; Cheeseman, H.; Cashin-Cox, M.; Naarding, M.; Clark, L.; Fernandez, N.; et al. A phase I double blind, placebo-controlled, randomized study of a multigenic HIV-1 adenovirus subtype 35 vector vaccine in healthy uninfected adults. PLoS ONE 2012, 7, e41936. [CrossRef]

29. Pandey, A.; Singh, N.; Vemula, S.V.; Couëtil, L.; Katz, J.M.; Donis, R.; Sambhara, S.; Mittal, S.K. Impact of preexisting adenovirus vector immunity on immunogenicity and protection conferred with an adenovirus-based H5N1 influenza vaccine. PLoS ONE 2012, 7, e33428. [CrossRef]

30. O'Hara, G.A.; Duncan, C.J.A.; Ewer, K.J.; Collins, K.A.; Elias, S.C.; Halstead, F.D.; Goodman, A.L.; Edwards, N.J.; Reyes-Sandoval, A.; Bird, P.; et al. Clinical assessment of a recombinant simian adenovirus ChAd63: A potent new vaccine vector. J. Infect. Dis. 2012, 205, 772-781. [CrossRef]

31. Sun, Y.; Li, H.-Y.; Tian, D.-Y.; Han, Q.-Y.; Zhang, X.; Li, N.; Qiu, H.-J. A novel alphavirus replicon-vectored vaccine delivered by adenovirus induces sterile immunity against classical swine fever. Vaccine 2011, 29, 8364-8372. [CrossRef] [PubMed]

32. Rhee, E.G.; Kelley, R.P.; Agarwal, I.; Lynch, D.M.; Porte, A.L.; Simmons, N.L.; Clark, S.L.; Barouch, D.H. TLR4 Ligands Augment Antigen-Specific CD8+ T Lymphocyte Responses Elicited by a Viral Vaccine Vector. J. Virol. 2010, 84, 10413-10419. [CrossRef] [PubMed]

33. Steitz, J.; Barlow, P.G.; Hossain, J.; Kim, E.; Okada, K.; Kenniston, T.; Rea, S.; Donis, R.O.; Gambotto, A. A Candidate H1N1 Pandemic Influenza Vaccine Elicits Protective Immunity in Mice. PLoS ONE 2010, 5. [CrossRef] [PubMed]

34. Richardson, J.S.; Yao, M.K.; Tran, K.N.; Croyle, M.A.; Strong, J.E.; Feldmann, H.; Kobinger, G.P. Enhanced protection against Ebola virus mediated by an improved adenovirus-based vaccine. PLoS ONE 2009, 4, e5308. [CrossRef]

35. Rodrigues, E.G.; Zavala, F.; Eichinger, D.; Wilson, J.M.; Tsuji, M. Single immunizing dose of recombinant adenovirus efficiently induces CD8+ T cell-mediated protective immunity against malaria. J. Immunol. Baltim. Md 1950 1997, 158, 1268-1274. 
36. Ophorst, O.J.A.E.; Radosević, K.; Klap, J.M.; Sijtsma, J.; Gillissen, G.; Mintardjo, R.; van Ooij, M.J.M.; Holterman, L.; Companjen, A.; Goudsmit, J.; et al. Increased immunogenicity of recombinant Ad35-based malaria vaccine through formulation with aluminium phosphate adjuvant. Vaccine 2007, 25, 6501-6510. [CrossRef]

37. Widjojoatmodjo, M.N.; Bogaert, L.; Meek, B.; Zahn, R.; Vellinga, J.; Custers, J.; Serroyen, J.; Radošević, K.; Schuitemaker, H. Recombinant low-seroprevalent adenoviral vectors Ad26 and Ad35 expressing the respiratory syncytial virus (RSV) fusion protein induce protective immunity against RSV infection in cotton rats. Vaccine 2015, 33, 5406-5414. [CrossRef]

38. Capone, S.; Meola, A.; Ercole, B.B.; Vitelli, A.; Pezzanera, M.; Ruggeri, L.; Davies, M.E.; Tafi, R.; Santini, C.; Luzzago, A.; et al. A novel adenovirus type 6 (Ad6)-based hepatitis $C$ virus vector that overcomes preexisting anti-ad5 immunity and induces potent and broad cellular immune responses in rhesus macaques. J. Virol. 2006, 80, 1688-1699. [CrossRef]

39. Ophorst, O.J.A.E.; Radošević, K.; Havenga, M.J.E.; Pau, M.G.; Holterman, L.; Berkhout, B.; Goudsmit, J.; Tsuji, M. Immunogenicity and Protection of a Recombinant Human Adenovirus Serotype 35-Based Malaria Vaccine against Plasmodium yoelii in Mice. Infect. Immun. 2006, 74, 313-320. [CrossRef]

40. Hashimoto, M.; Boyer, J.L.; Hackett, N.R.; Wilson, J.M.; Crystal, R.G. Induction of Protective Immunity to Anthrax Lethal Toxin with a Nonhuman Primate Adenovirus-Based Vaccine in the Presence of Preexisting Anti-Human Adenovirus Immunity. Infect. Immun. 2005, 73, 6885-6891. [CrossRef]

41. Pinto, A.R.; Fitzgerald, J.C.; Giles-Davis, W.; Gao, G.P.; Wilson, J.M.; Ertl, H.C.J. Induction of CD8+ T cells to an HIV-1 antigen through a prime boost regimen with heterologous E1-deleted adenoviral vaccine carriers. J. Immunol. Baltim. Md 1950 2003, 171, 6774-6779. [CrossRef] [PubMed]

42. Casimiro, D.R.; Chen, L.; Fu, T.-M.; Evans, R.K.; Caulfield, M.J.; Davies, M.-E.; Tang, A.; Chen, M.; Huang, L.; Harris, V.; et al. Comparative immunogenicity in rhesus monkeys of DNA plasmid, recombinant vaccinia virus, and replication-defective adenovirus vectors expressing a human immunodeficiency virus type 1 gag gene. J. Virol. 2003, 77, 6305-6313. [CrossRef] [PubMed]

43. Xiang, Z.; Gao, G.; Reyes-Sandoval, A.; Cohen, C.J.; Li, Y.; Bergelson, J.M.; Wilson, J.M.; Ertl, H.C.J. Novel, Chimpanzee Serotype 68-Based Adenoviral Vaccine Carrier for Induction of Antibodies to a Transgene Product. J. Virol. 2002, 76, 2667-2675. [CrossRef] [PubMed]

44. Xiang, Z.Q.; Yang, Y.; Wilson, J.M.; Ertl, H.C. A replication-defective human adenovirus recombinant serves as a highly efficacious vaccine carrier. Virology 1996, 219, 220-227. [CrossRef]

45. Eloit, M.; Adam, M. Isogenic adenoviruses type 5 expressing or not expressing the E1A gene: Efficiency as virus vectors in the vaccination of permissive and non-permissive species. J. Gen. Virol. 1995, 76, 1583-1589. [CrossRef] [PubMed]

46. Neilan, J.G.; Schutta, C.; Barrera, J.; Pisano, M.; Zsak, L.; Hartwig, E.; Rasmussen, M.V.; Kamicker, B.J.; Ettyreddy, D.; Brough, D.E.; et al. Efficacy of an adenovirus-vectored foot-and-mouth disease virus serotype A subunit vaccine in cattle using a direct contact transmission model. BMC Vet. Res. 2018, 14. [CrossRef]

47. Tang, A.; Freed, D.C.; Li, F.; Meschino, S.; Prokop, M.; Bett, A.; Casimiro, D.; Wang, D.; Fu, T.-M. Functionally inactivated dominant viral antigens of human cytomegalovirus delivered in replication incompetent adenovirus type 6 vectors as vaccine candidates. Hum. Vaccines Immunother. 2017, 13, 2763-2771. [CrossRef]

48. Fonseca, J.A.; McCaffery, J.N.; Kashentseva, E.; Singh, B.; Dmitriev, I.; Curiel, D.T.; Moreno, A. A prime-boost immunization regimen based on a Simian Adenovirus 36 vectored multi-stage malaria vaccine induces protective immunity in mice. Vaccine 2017, 35, 3239-3248. [CrossRef]

49. Nazerai, L.; Bassi, M.R.; Uddback, I.E.M.; Holst, P.J.; Christensen, J.P.; Thomsen, A.R. Early life vaccination: Generation of adult-quality memory CD8+ T cells in infant mice using non-replicating adenoviral vectors. Sci. Rep. 2016, 6, 38666. [CrossRef]

50. Penaloza-MacMaster, P.; Alayo, Q.A.; Ra, J.; Provine, N.M.; Larocca, R.; Lee, B.; Barouch, D.H. Inhibitory receptor expression on memory CD8 T cells following Ad vector immunization. Vaccine 2016, 34, 4955-4963. [CrossRef]

51. Manzoli, L.; Flacco, M.E.; D’Addario, M.; Capasso, L.; Vito, C.D.; Marzuillo, C.; Villari, P.; Ioannidis, J.P.A. Non-publication and delayed publication of randomized trials on vaccines: Survey. BMJ 2014, 348. [CrossRef] [PubMed]

52. Gallaher, S.D.; Berk, A.J. A rapid Q-PCR titration protocol for adenovirus and helper-dependent adenovirus vectors that produces biologically relevant results. J. Virol. Methods 2013, 192, 28-38. [CrossRef] [PubMed] 
53. Darrah, P.A.; Patel, D.T.; De Luca, P.M.; Lindsay, R.W.B.; Davey, D.F.; Flynn, B.J.; Hoff, S.T.; Andersen, P.; Reed, S.G.; Morris, S.L.; et al. Multifunctional T H 1 cells define a correlate of vaccine-mediated protection against Leishmania major. Nat. Med. 2007, 13, 843-850. [CrossRef] [PubMed]

54. Billeskov, R.; Wang, Y.; Solaymani-Mohammadi, S.; Frey, B.; Kulkarni, S.; Andersen, P.; Agger, E.M.; Sui, Y.; Berzofsky, J.A. Low Antigen Dose in Adjuvant-Based Vaccination Selectively Induces CD4 T Cells with Enhanced Functional Avidity and Protective Efficacy. J. Immunol. Baltim. Md 1950 2017, 198, 3494-3506. [CrossRef]

(C) 2020 by the authors. Licensee MDPI, Basel, Switzerland. This article is an open access article distributed under the terms and conditions of the Creative Commons Attribution (CC BY) license (http://creativecommons.org/licenses/by/4.0/). 